\title{
Transgenic Plant expressed Hemaggulutinin against Low Pathogenic Avian Influenza Virus
}

\author{
Short title: Transgenic plant vaccine against avian influenza. \\ Hongzhuan Wu ${ }^{1 \star}$, Karyn Scissum-Gunn ${ }^{1}$, Lula Smith ${ }^{1}$ and Joseph J Giambrone ${ }^{2}$ \\ ${ }^{1}$ Department of Biological Sciences, Alabama State University, AL, 36101, USA \\ ${ }^{2}$ Department of Poultry Science, Auburn University, AL, 36849, USA
}

\section{Article Info}

*Corresponding author:
Hongzhuan Wu
Professor
Department of Biological Sciences
Alabama State University
AL 36849
USA
E-mail: hwu@alasu.edu

Received: June 29, 2017

Accepted: August 12, 2017

Published: August 18, 2017

Citation: Wu H, Scissum-Gunn K, Smith L, Giambrone JJ. Transgenic Plant Expressed Hemaggulutinin against Low Pathogenic Avian Influenza Virus. Madridge J Clin Res. 2017; 1(1): 10-14

doi: $10.18689 /$ mjcr-1000102

Copyright: $\odot 2017$ The Author(s). This work is licensed under a Creative Commons Attribution 4.0 International License, which permits unrestricted use, distribution, and reproduction in any medium, provided the original work is properly cited.

Published by Madridge Publishers

\begin{abstract}
Avian influenza virus (AIV) can cause severe disease in poultry flocks worldwide. Highly pathogenic (HP) H5N1and H7N9 AlVs are important causes of morbidity and mortality. Effective vaccines against Al in poultry need to be developed for use in emergency responses for a limited area to stop viral spread. A transgenic Arabidopsis expressing the hemagglutinin (HA) gene of the low pathogenic LPH1N1sub type was constructed, and immune response evaluated in chickens. The study demonstrated that chickens given high or low doses of HA transgenic total soluble protein (TSP) orally had a higher $\mathrm{HI}$ antibody, enhanced cytokine responses, and a reduction in virus shedding compared to chickens given a commercial inactivated vaccine after challenge. In addition, chickens given the transgenic plant vaccine (TPV) had better weight gain than those given the commercial vaccine. The TPV has the potential to serve as a vaccine against AIV inpoultry.
\end{abstract}

Keywords: Avian Influenza Virus; HA; H1N1; Transgenic plant; Vaccine.

Abbreviations: AIV: Avian Influenza Virus; HA: Hemagglutinin; ELISA: = Enzyme Linked Immunosorbent Assay; EMM: Edinburgh Minimal Medium: Ig: Immunoglobulin; OD: Optical Density; PAGE: Polyacrylamide Gel Electrophoresis; PBS: phosphate Buffered Saline; PCR: Polymerase Chain Reaction; qRRT-PCR: Quantitate Real-Time ReverseTranscriptase-Polymerase Chain Reaction; RT: Reverse Transcription; SDS: Sodium Dodecyl Sulfate; SPF: Specific-Pathogen Free; TE: TRIS EDTA; wks: Weeks.

\section{Introduction}

Alisan important viral disease that is spreading worldwide in poultry. AIVs are subdivided using hemagglutinin (HA) and neuraminidase (NA) proteins. AIVs are also divided into high pathogenic (HP) and low pathogenic (LP) types. HPAIVs cause severe morbidity and mortality, whereas LPAIVs cause only mild respiratory disease. In addition, the virus is genetically unstable and LPAIVs can mutate into HPAIVs at the same farm. AIVs infect a variety of animals including chickens, quail, turkeys, ducks, geese, pigs, and humans [1]. The recent pandemic outbreak of influenza virus in humans, which was caused by the H1N1 contained part of an avian-originated HA sequence [3].

Control of $\mathrm{Al}$ in poultry in modern countries is done using quarantine measures, culling of infected poultry flocks, and improved biosecurity. Vaccination in emergency situations maybe important to limit disease outbreaks. In less developed countries, where AIVs are endemic, vaccines are routinely used. These vaccines often produced low efficacy. 
The following strategies have been developed for AIV vaccines: recombinant, subunit hemagglutinin inactivated proteins, reverse genetic, and DNA vaccines $[4,5,6,7,8,10$, $12,13,14,15,16,17,18,19]$. Edible vaccines are cost effective, easily stored, are transported without degradation or damage, and their production time and cost are minimal compared to conventionally produced vaccines [9]. The hemagglutinin (HA) surface glycoprotein promotes influenza virus entry and is the key protective antigen in natural infections and vaccinations. In this study, a transgenic Arabidopsis, which incorporated the HA gene of LP AIV, was developed and its efficacy tested in chickens.

\section{Materials and Methods}

Animals: Broilers having no maternal antibodies against AIV from the Auburn University poultry farm were used. All were given feed and water ad libitum. They were reared in isolation units maintained with filtered air under positive pressure following the guidelines of the Auburn University Institutional Animal Care and Use Committee guidelines.

Extraction of viral RNA. RNA was extracted from allantoic fluid of embryos infected with AIV. The RNA was extracted using a Trizol RNA (Invitrogen, Carlsbad, CA). Anti-AIV poly sera, were provided by Lohmann, Inc. (Winslow, ME).

Construction of HA plant expression cassette. The HA CDNA was prepared from RNA using an RT-PCR preamplification system (GIBCO-BRL, Grand Island, NY). Primers flanking the HA sequence were designed according to information in the GenBank and with restriction sites for directional cloning of amplified sequences as shown below:

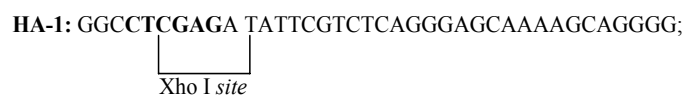

HA-2: GGCTCTAGACATATCGTCTCGTATTAGTAGAAACAAGGGTGTTTT Xba I site

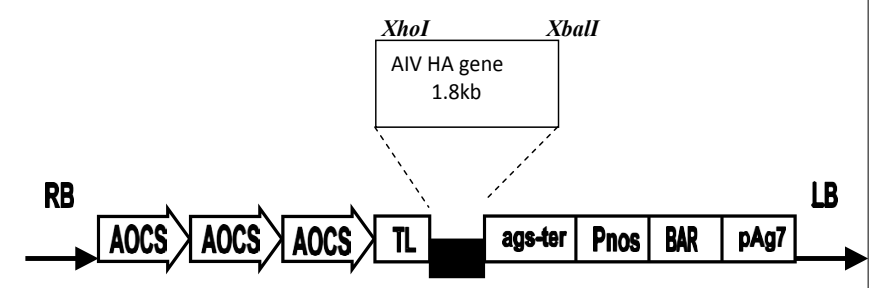

pMSP-2

Figure 1. Structure of the T-DNA region of rpE-HA vector was used for expression of HA gene. HA from TA vector with Xho I and Xba I was cloned in the plant-binary vector, pE1857 under control of super promoter. Resulting plasmid was designated as rpE-HA. The selectable marker for plant transformation was BAR gene, which conferred resistance to bialaphos. LB and RB indicate the left and right borders of the T-DNA region. AOCS represented the Agrobacterium octopine synthetase promoter. TL represented translational leader sequence. ags-ter represents the agropine synthase terminator region. Pnos represented the bacterial kanamycin selection marker. BAR represented the bialophos resistance plant selectable marker gene, and pAG7 represents terminator sequence.pMSP-2 represented one of the binary vectors.
The plant expression vector pE1857 [23] was obtained from a patent transfer agreement (S. Gelvin, personal communication). The vector was derived from a kanamycinresistant pGPTV plasmid containing the patented superpromoter, TEV translational leader, polylinker derived from pBluescript, and ags terminator in pUC119. The PCR amplification product was electrophoresed after $X b a I$ and Xhol digestion, purified using a Geneclean II kit (Qbiogene, Inc., Carlsbad, $\mathrm{CA}$ ) and cloned into the plant expression vector, pE1857. This construct was designated rpE-HA (Fig.1). The insert sequence was confirmed by DNA sequencing (Auburn University Sequencing Laboratory).

Selection of transgenic plants. The rpE- HA and the control vector, pE1857 were introduced into Agrobacterium tumefaciens strain $\mathrm{C} 58 \mathrm{C} 1$ by electroporation and used to transform $A$. thaliana by vacuum infiltration [22]. Seeds were harvested from the self-pollinated primary transformants to generate plants for screening. Seedlings germinating in Promix potting medium were sprayed every day for 3 days with a solution of $50 \mathrm{mg} / \mathrm{ml}$ of bialaphos (Sigma Co. Creamville, N. J.). After 5 days, procedures were repeated for an additional 3 days. Seeds from surviving plants were harvested for bialaphos selection and performed for 3 additional generations to obtain homozygous transgenic lines. Plants resistant to bialophos (glufosinate) and showing homozygous segregation were selected.

Analysis HA gene expression in plants. The HA transgenes were demonstrated by real time RT-PCR [23]. Total RNA from transgenic and wild type $A$. thaliana were obtained from $1 \mathrm{~g}$ of leaf tissues by an RNA isolation system (Omega Bio-tek, Inc, GA). Real time RT- PCR was performed in the ABI 7300 real-time PCR system (Foster, CA) using Quantitect SYBR Green RT-PCR kit (Mainz, Germany) using the manufacturer's instructions.

Expression of HA protein was confirmed by western blot. Leaves $(\sim 1 \mathrm{~g})$ were ground to a powder in liquid nitrogen and added to $1 \mathrm{ml}$ of extraction buffer (10 $\mathrm{mM}$ 2(N-morpholino) ethanesulfonic acid (Mes), pH 6.0, $10 \mathrm{mM} \mathrm{NaCl}, 5 \mathrm{mM}$ EDTA, $0.6 \%$ Triton $\mathrm{X}-100,0.25 \mathrm{M}$ sucrose, $0.15 \mathrm{mM}$ spermine, 0.5 $\mathrm{mM}$ spermidine, $10 \mathrm{mM}$ DTT, and $1 \mathrm{mM}$ phenylmethyl sulfonyl fluoride). Homogenates were centrifuged twice at $12,000 \times \mathrm{g}$ for $15 \mathrm{~min}$ at $40 \mathrm{C}$ to remove insoluble debris and supernatants subjected to SDS-PAGE followed by electro blotting onto nitrocellulose membranes using BioRad Semi-dry Trans Blotter (BIO-RAD, Hercules, CA). Membranes were blocked with $3 \%$ skim milk and probed with polyclonal anti-AIV chicken sera at a 1:500 dilution. Immune complex was detected by horseradish peroxidase (HRP)-conjugated antichicken immunoglobulin $G$ (Jackson ImmunoResearch Laboratories Inc., West Grove, PA) at a 1:1000 dilution.

Total soluble protein (TSP) concentrations were determined using Bradford assay [2]. HA protein concentrations were determined by antigen-capture (AC) ELISA [21]. Plates were coated at $4 O C$ overnight with polyclonal anti-HA-chicken serum diluted at 1:1000 in PBS buffer $\mathrm{pH}$ 8.0, washed 3 times with PBST (phosphate-buffered 
saline with $0.05 \%$ Tween-20) buffer, and blocked with PBST buffer containing $5 \%$ skim milk at $37 \mathrm{OC}$ for $3 \mathrm{hr}$. Plates were washed 3 times with PBST and dried and stored at $40 C$.

\section{Vaccination and Challenge}

One-day-old chickens were placed into 5 groups at 10 birds per group. Chickens in groups 1 and 2 were orally given $50 \mu \mathrm{g}$ and $100 \mu \mathrm{g}$ total leaf proteins respectively, containing the HA in $1 \mathrm{ml}$ of saline weekly for 3 consecutive weeks. Groups 3 chickens received orally $125 \mu \mathrm{g}$ protein extracted from wild type Arabidopsis in $1 \mathrm{ml}$ of saline Group 4 birds were given a single dose of commercial inactivated vaccine (Lohman Inc., Winslow, ME) intramuscularly and group 5 chickens received orally the Arabidopsis containing only the pE1857 vector in $1 \mathrm{ml}$ of saline, respectively; Sera from 10 birds were collected at day of age by exsanguination and tested for material antibody (AB) against AIV. The remaining birds were bleed weekly post vaccination (PV) and tested by hemagglutination inhibition (HI). Spleens from one chicken / group were collected weekly and 3 at the end of the trial, using real- time quantitative PCR to detect cellular immune responses as measured by IL-2 and IL- 6 cytokines. At day 23 $P V$, chickens were challenged with $0.2 \mathrm{ml}$ of 108.5 TCID50 of LP H1N1 AIV by nose and eye drop. This AIV was isolated from healthy hunter killed ducks in Lake City, FL. We used this LP virus, because we lack BL3 containment. Chickens were monitored for 1 week post-challenge (PC) for clinical signs. Oropharyngeal and cloaca swabs were collected for virus isolation from each group at 3,5, and 7 days PC. Swabs were placed in PBS and RNA was extracted and evaluated by RT$P C R$ to determine virus shedding.

Hemagglutination inhibition (HI): Serum samples were heat inactivated at $560 \mathrm{C}$ for $30 \mathrm{~min}$. HA units were determined before each assay using two-fold dilutions. Sera were diluted twofold in $25 \mu \mathrm{l} \mathrm{PBS}$, and $4 \mathrm{HAs}$ of H1N1 used in $25 \mu \mathrm{l}$. Contents of each well were mixed and plates were incubated for $30 \mathrm{~min}$ at room temperature (RT). Finally, $50 \mu \mathrm{l}$ of a $0.5 \%$ chicken erythrocyte suspension was added to each well. The highest dilution preventing hemagglutination was the HI titer. Data were reported as geometric means with standard deviation from three independent replicates.

ELISA testing: Blood was collected at weekly intervals $A B$ determined with an enzyme- linked immunosorbent assay (ELISA) kit (Synbiotics Co, Kansas City, MO) following published protocols [20]. Plates were coated with $100 \mu \mathrm{IIV}$; blocked and then ten-fold serials of serum were added to designated wells overnight. Plates were incubated for $1 \mathrm{~h}$ at RT, washed, followed by addition of HRP-conjugated goat-

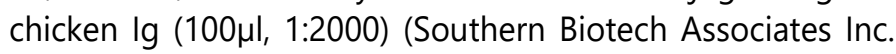
(SBA), Birmingham, AL). 100 $\mu$ l TMB substrate was used for enzyme reactions and the absorbance read at $450 \mathrm{~nm}$ using a Tecan ELISA plate reader (Tecan Inc., Research Triangle Park, NC).

\section{Reverse transcription and quantitative PCR (qRT-PCR) for} cytokine analysis: Total RNA was extracted from spleens using TRIzol (Invitrogen, Carlsbad, CA) as described by the manufacturer. Five micrograms of total RNA were treated with 1.0 unit of DNAse I and $1.0 \mu \mathrm{\mu l}$ of $10 \mathrm{x}$ reaction buffer (Sigma, St. Louis, MO), incubated for $15 \mathrm{~min}$ at RT, $1.0 \mu \mathrm{l}$ of stop solution was added to inactivated DNase I, and the mixture heated at $70{ }^{\circ} \mathrm{C}$ for $10 \mathrm{~min}$. Total RNA was reverse transcribed using Superscript first-strand synthesis system (Invitrogen, Carlsbad, CA) according to manufacturer's recommendations.

Table 1. Total soluble protein concentration in Arabidopsis.

\begin{tabular}{|c|l|c|c|}
\hline $\begin{array}{c}\text { Transgenic } A . \\
\text { Thaliana line }\end{array}$ & $\begin{array}{l}\text { TSPA } \\
\text { Concentration }(\mathrm{mg} / \mathrm{mL})\end{array}$ & $\begin{array}{c}\text { HA } \\
\text { concentration }(\mu \mathrm{g} / \mathrm{mL})\end{array}$ & $\begin{array}{c}\mathrm{HA} / \mathrm{TSP} \\
(\%)\end{array}$ \\
\hline $\mathrm{H}-1$ & 0.121 & 0.074 & 0.61 \\
\hline $\mathrm{H}-2$ & 0.098 & 0.052 & 0.53 \\
\hline $\mathrm{H}-3$ & 0.15 & 0.087 & 0.58 \\
\hline Control (Al) & 0.021 & 0.001 & 0.06 \\
\hline
\end{tabular}

A Total Soluble Protein $=$ TSP

Primers for cytokines and GAPDH controls were based upon sequences from public databases (Table 1). Amplification and detection used equivalent amounts of total RNA from spleens using the QuantiTect SYBR Green PCR kit (Qiagen, Valencia, $C A$ ).

QPCR data analysis: Relative transcriptional levels of different genes were determined by subtracting the cycle threshold (Ct) of the sample by that of the GAPDH, the calibrator or internal control, as per the formula: $\Delta \mathrm{Ct}=\mathrm{Ct}$ (sample)- $\mathrm{Ct}$ (calibrator). The relative expression levels of the specific gene in TP vaccinated chickens were compared to that in nonvaccinated chickens and calculated using the formula $2 \Delta \Delta \mathrm{Ct}$ where $\Delta \Delta \mathrm{Ct}=\Delta \mathrm{Ct}$ (vaccinated) $\Delta \mathrm{Ct}$ (non- vaccinated). Each analysis was performed in triplicate. Data were analyzed by analysis of variance (ANOVA) using SigmaStat statistical analysis software (Systat Software, San Jose, CA). Statistical significance was set at $\mathrm{P}<0.05$.

\section{Results}

Stable integration and expression of transgene in $A$. thaliana: Fifty -six (56) transgenic A. thaliana lines were selected. HA DNA was not detected in control plants transformed with pE1857 or untransformed plants. Chickens given TPs at high or low levels expressed HA protein, showed about $10-20 \%$ reduced growth PC compared to chickens given the wild type Arabidopsis control plants or plants transformed with the pE1857.

Determination of HA protein in plants: Western blotting showed $76 \mathrm{KD}$ protein in 56 plants,but was absent in the untransformed plants(Datanotshown).The HAprotein expressed in thaliana lines ranged from $0.53 \%-0.61 \%$ of TSP (Table 1). Transgenic line HA -1 had the highest HA expression. Higher levels of HA protein expression were consistent with higher copy number of the HAtransgene.

Challenge protection: No clinical signs were observed in any group after challenge. 


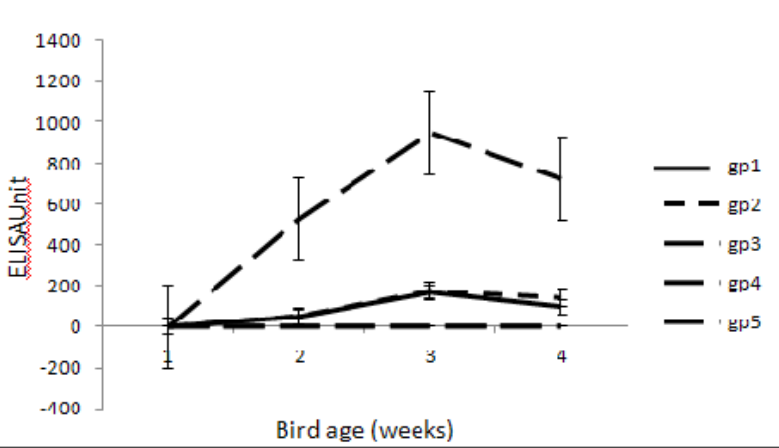

Figure 2. ELISA. Sera were taken from each group at weekly intervals. Birds were challenged at the end of fourth week with AIV H1N1 strain. ELISA units were interpreted according to the manufacture's instruction (Synbiotics, Kansas City, MO). Serum from day-old chicks did not have $A B$ against AIV.

Total $A B$ titers are listed in figure 2 , the highest titers were in chickens vaccinated with commercial vaccine. Incontrast, chickens given plant-derived HAprotein showed a lower increase in titers. Chickens feed with either $50 \mu \mathrm{g}$ or $100 \mu \mathrm{g}$ had no significant differences in $A B$ increase.

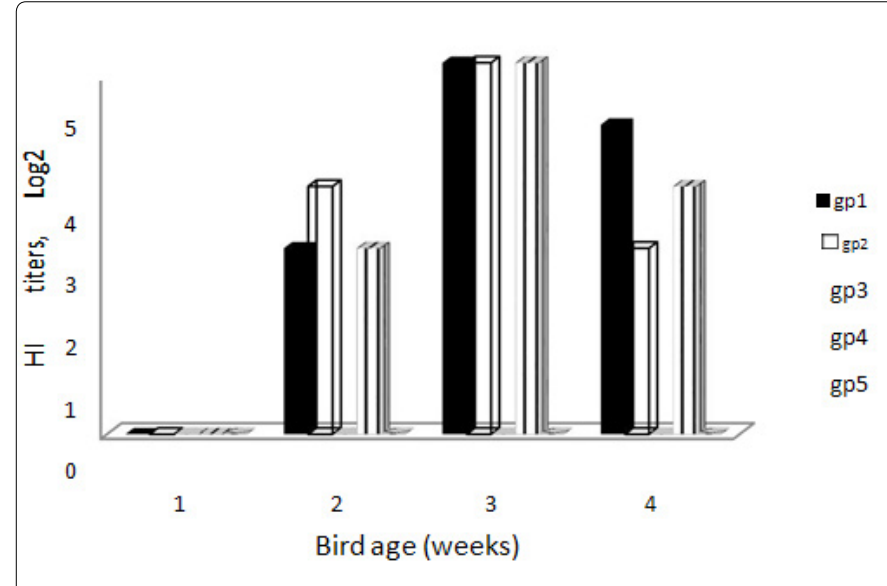

Figure 3. $\mathrm{HI} A B$. Data represented the mean $(\mathrm{N}=10) \pm S$. $D$ for anti-AIV $A B$ titers as determined in triplicate by $\mathrm{HI}$

HIs of the poly anti-sera were shown in figure 3. Anti-H1 hemagglutinin was detected in groups feed either with $50 \mu \mathrm{g}$ or $100 \mu \mathrm{g}$. HItiteralsohad little differences between the two groups, or group given the commercial vaccine.

Cell mediated immune response-cytokine levels are shown in figure 4. The subsets of Th cells were distinguished by the pattern of cytokines. To distinguish between the activation of Th cells of the Th1 and Th2 subsets, the expression levels of mRNA encoding a panel of chicken cytokines were quantified in spleen lymphocyte following vaccination. Compared with negative controls(group3\&5), transcripts of the cytokines IL-2 in groups feed with $50 \mu \mathrm{g}$ and $100 \mu \mathrm{g}$ were increased 100-fold and 115-fold respectively after third week post vaccination, whereas commercial vaccine administered group increased 118-fold, which was a significant increase of the Th1 cytokine production. The increased Th2 cytokine IL-10 was not as obvious as Th1.IL-10 levels in groups given $50 \mu \mathrm{g}$ and $100 \mu \mathrm{g}$ were similar, increased 22-fold and 23-fold respectively, the group injected with commercial vaccine increased35-fold.

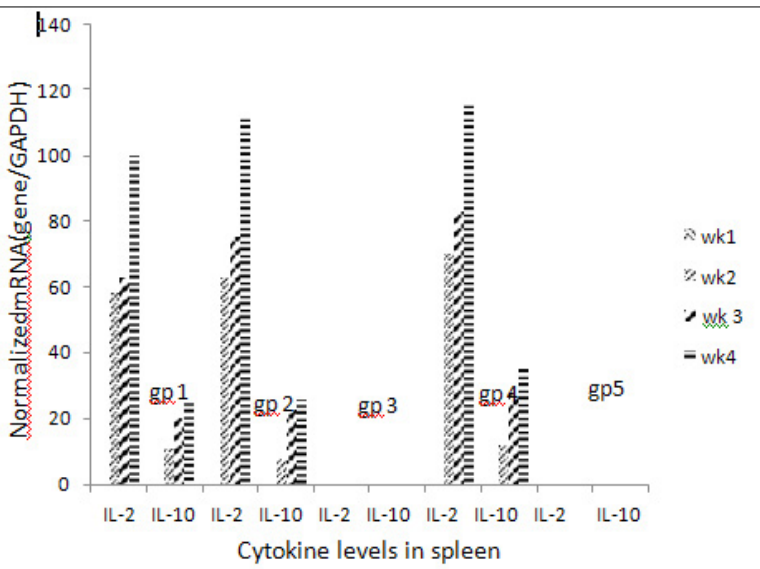

Figure 4. Cytokine analysis. One-day-old broiler chickens were placed into 5 groups with 10 birds in each group. Chickens in groups 1 and 2 were given $50 \mu \mathrm{g}$ and $100 \mu \mathrm{g}$ total leaf proteins respectively, at weekly intervals for 3 consecutive weeks. Group 3 birds received $125 \mu$ g protein extracted from wild type Arabidopsis and $1 \mathrm{ml}$ of saline, respectively. Group 4 birds were given a single dose of commercial vaccine. Chickens in group 5 received Arabidopsis the pE1857 vector. One week after the third immunization, the expression levels of mRNA in splenocytes encoding chicken cytokines were quantified using qRRT-PCR.

Table 2. Virus shedding in chickens given $0.2 \mathrm{ml}$ of $10^{8.5} / 50 \mu \mathrm{ITCID} 50$ of H1N1 AIV.

\begin{tabular}{|l|r|l|r|l|r|l|}
\hline Group & $d p c$ & $A, B 3$ & $d p c$ & 5 & $d p c$ & 7 \\
\hline & $T^{c}$ & $C^{c}$ & $T^{c}$ & $C^{C}$ & $T^{C}$ & $C^{C}$ \\
\hline Gp1 & $7 / 7^{\mathrm{D}}$ & $7 / 7$ & $6 / 7$ & $5 / 7^{\mathrm{b}}$ & $3 / 7$ & $3 / 7^{\mathrm{b}}$ \\
\hline Gp2 & $7 / 7$ & $7 / 7$ & $3 / 7$ & $2 / 7^{\mathrm{a}}$ & $3 / 7$ & $1 / 7^{\mathrm{a}}$ \\
\hline Gp3 & $7 / 7$ & $7 / 7$ & $7 / 7$ & $7 / 7^{\mathrm{b}}$ & $7 / 7$ & $7 / 7^{\mathrm{c}}$ \\
\hline Gp4 & $7 / 7$ & $7 / 7$ & $2 / 7$ & $1 / 7^{\mathrm{a}}$ & $3 / 7$ & $1 / 7^{\mathrm{a}}$ \\
\hline Gp5 & $7 / 7$ & $7 / 7$ & $7 / 7$ & $7 / 7^{\mathrm{b}}$ & $7 / 7$ & $7 / 7^{\mathrm{c}}$ \\
\hline
\end{tabular}

A. dpc: Days post-challenge

B. Number of birds shedding virus/total

C. $\mathrm{T}=$ trachea; $\mathrm{C}=$ Cloacal

D. Numbers within the same column with different superscript $(a, b, c)$ statistically significant, $P<0.05$.

Virus shedding data are shown in table 2. Consistent with a previous study, positive samples were defined as those yielding a two-well positive amplification with a $\mathrm{Ct}$ value of $\leq$ 38. Groups given the TP showed shedding to be reduced 5 days post challenge $(\mathrm{dpc})$ in both trachea and cloacal. Group2 birds had a greater effect in reducing virus shedding then group1, and has same effect as commercial vaccine group by $7 \mathrm{dpc}$. Chickens in group 2 feed with $100 \mu \mathrm{g}$ TP had the best body weight gain (Fig.5).

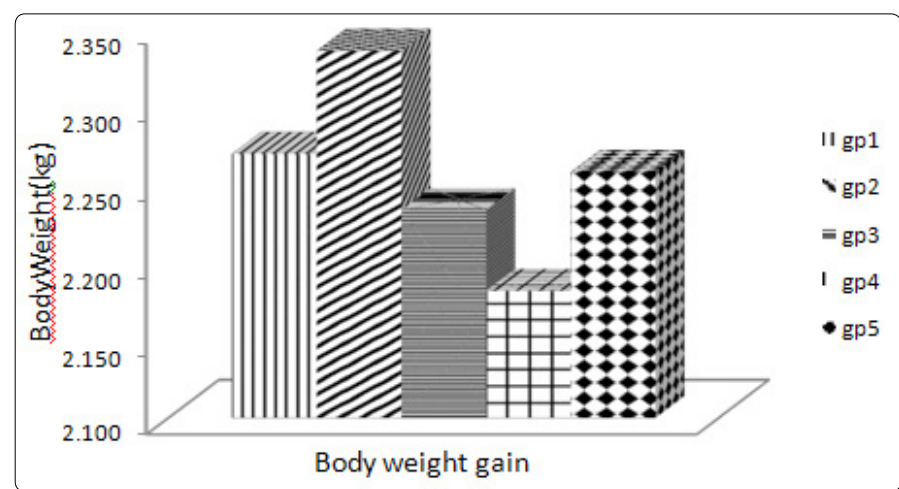

Figure 5. Effect of vaccine dose on body weight. Chickens in groups 1 and 2 were given $50 \mu \mathrm{g}$ and $100 \mu \mathrm{g}$ total leaf proteins respectively at weekly intervals for 3 consecutive weeks. 


\section{Discussion}

Current edible vaccines have low expression and low efficacy. The TPVs have been studied for nearly thirty years, but few commercial applications have been reported. Data herein showed a significant concentration of HA protein expression in the TPV. This compared favorably with previous expression in $A$. thaliana of VP2 protein of infectious bursal disease virus and the sigma $C$ protein of avian reovirus [23], [24]. The $\mathrm{HI}$ assay is commonly used for the detection of antibodies to influenza viruses. However, for the detection of antibodies to avian influenza viruses of the H1N1 subtype either induced by infection or by vaccination, the $\mathrm{HI}$ assay isles sensitive. Therefore, VN assay is a more efficacious method of choice to detect serum antibodies directed to these viruses.

Th1 cells produce IFN $-\gamma$ and IL-2, which play a critical role in CMI. Th2 cells produce IL-4, IL-5, IL-10, and IL-13 [11]. Results showed high IL-2 expression, which suggested that the $\mathrm{TH} 1$ immune response may play a role in the efficacy of the TPV, as shown by reduced virus- shedding compared to the challenged birds, which received the commercial vaccine.

Results showed that TPV induced a moderate anti-AIV HI $A B$ response and reduced virus shedding in chickens when compared to chickens that received the commercial vaccine. The TPV also induced CMI related cytokines and has a potential for use in commercial AIV vaccines in poultry.

\section{Acknowledgment}

Research was supported by Minority Access to Research Careers (MARC) program awardedto Karyn Scissum-Gunn and also supported by a USDA-IFAFS grant (\#:00-52100-9705). We are grateful to Teresa Dormitorio and Chia-Chen Weng for their technical help.

\section{References}

1. Alexander DJ. A review of avian influenza in different bird species. Vet. Microbiol. 2000; 74: 3.

2. Bradford MM. A rapid and sensitive method for the quantitation of microgram quantities of protein utilizing the principle of protein-dye binding. Anal Biochem. 1976; 72: 248-254.

3. Brammer $L$, Blanton $L$, Epperson $S$, et al. Surveillance for Influenza during the 2009 Influenza A (H1N1) Pandemic - United States April 2009 - March 2010. ClinInfectDis. 2011; 52: 27- 35. doi: 10.1093/cid/ciq009

4. Chambers TM, Kawaoka Y, Webster RG. Protection of chickens from lethal influenza infection by vaccine expressed hemagglutinin. Virology. 1988; 167(2): 414-421. doi: 10.1016/0042-6822(88)90103-1

5. Crawford J, Wilkinson B, Vosnesensky A, et al. Baculovirus-derived hemagglutinin vaccines protect against lethal influenza infections by avian $\mathrm{H} 5$ and $\mathrm{H} 7$ subtypes. Vaccine. 1999; 17(18): 2265-2274. doi: 10.1016/ S0264-410X(98)00494-0

6. Davis AR, Bos $T$, Ueda M, et al. Immune response to human influenza virus hemagglutinin expressed in Escherichia coli. Gene. 1983; 21(3): 273284. doi: 10.1016/0378-1119(83)90011-2

7. Fodor E, Devenish L, Engelhardt OG, et al. Rescue of influenza A virus from recombinant DNA. J Virol. 1999; 73: 9679-9682.
8. Gao W, Soloff AC, Lu X, et al. Protection of mice and poultry from lethal H5N1 avian influenza virus through adenovirus-based immunization. $J$ Virol. 2006; 80(4): 1959-1964. doi: 10.1128/JVI.80.4.1959-1964.2006

9. Haq TA, Mason HS, Clements JD, Arntzen CJ. Oral immunization with a recombinant bacterial antigen produced in transgenic plants. Science. 1995; 268: 714-716.

10. Hunt LA, Brown DW, Robinson HL, Naeve CW, Webster RG. Retrovirusexpressed hemagglutinin protects against lethal influenza virus infections. J Virol. 1988; 62: 3014-3019.

11. Hurk SV, Mapletoft JW, Arsic N, Kovacs-Nolan J. Immunopathology of RSV infection: prospects for developing vaccines without this complication. Reviews inMedical Virology. 2007; 17(1): 5-34. doi: 10.1002/rmv.518

12. Lee CW, Senne DA, Suarez DL. Generation of reassortant influenza vaccines by reverse genetics that allows utilization of a DIVA (differentiating infected fromvaccinated animals) strategy for the control of avian influenza. Vaccine. 2004; 22: 3175-3181. doi: 10.1016/j.vaccine.2004.01.055

13. Liu $\mathrm{M}$, Wood $\mathrm{JM}$, Ellis $\mathrm{T}$, et al. Preparation of a standardized, efficacious agricultural H5N3 vaccine by reverse genetics. Virology. 2003; 314(2): 580-590. doi: 10.1016-50042-6822(03)00458-6

14. Neumann G, Fujii K, Kino Y, Kawaoka Y. An improved reverse genetics system for influenza $A$ virus generation and its implications for vaccine production. Proc. Natl.Acad. Sci. USA. 2005; 102(46): 16825-16829.

15. Saelens $X$, Vanlandschoot $P$, Martinet $W$, et al. Protection of mice against a lethal influenza virus challenge after immunization with yeast-derived secreted influenza virus hemagglutinin. Eur. J. Biochem. 1999; 260(1): 166175.

16. Suarez DL, Schultz-Cherry S. The effect of eukaryotic expression vectors and adjuvants on DNA vaccines in chickens using an avian influenza model. Avian Dis. 2000; 44(4): 861- 868. doi: 10.2307/1593058

17. Swayne $D E$, Beck JR, Garcia $M$, Stone HD. Influence of virus strain andantigen mass on efficacy of $\mathrm{H} 5$ avian influenza inactivated vaccines. Avian Pathol. 1999; 28: 245- 255.

18. Tang M, Harp JA, Wesley RD. Recombinant adenovirus encoding the HA gene from swine H3N2 influenza virus partially protects mice from challenge with heterologous virus: A/HK/1/68 (H3N2). Arch. Virol. 2002; 147: 2125-2141.

19. Taylor J, Weinberg R, Kawaoka Y, Webster RG, Paoletti E. Protective immunity against avian influenza induced by a fowlpox virus recombinant. Vaccine. 1988; 6(6): 504-508. doi: 10.1016/0264-410X(88)90101-6

20. Trampel DW, Zhou EM, Yoon K J, Koehler K J. Detection of antibodies in serum and egg yolk following infection of chickens with an H6N2 avian influenza virus. J. Vet. Diagn. Invest. 2006; 18: 437-442. doi: $10.1177 / 104063870601800502$

21. Velumani $S, D u Q$, Fenner BJ, et al. Development of an antigen-capture ELISA for detection of $\mathrm{H} 7$ subtype avian influenza from Experimentally infected chickens. J Virol Methods. 2008; 147(2): 219-225. doi: 10.1016/j. jviromet.2007.09.004

22. Wu H, Singh NK, Gunn KS, Giambrone JJ. Research towards development of an edible vaccine for avian reovirus. Avian Dis. 2009; 53(3): 376-381. doi: 10.1637/8589-011309-Reg.1

23. Wu H, Singh NK, Locy RD, Scissum-Gunn K, Giambrone JJ. Expression of immunogenic VP2 protein of infectious bursal disease virus in Arabidopsis thaliana. Biotech. Letters. 2004; 26(10): 787-792.

24. Wu H, Singh NK, Robert DL, Scissum-Gunn K, Giambrone JJ. Immunization of chickens with VP2 protein of infectious bursal disease virus expressed in Arabidopsis thaliana. Avian Dis. 2004; 48(3): 663-668. doi: 10.1637/7074 